\title{
"Esa tranquilidad terrible". La identidad del perpetrador en el 'giro' victimario
}

\author{
Pablo Sánchez León \\ Universidade Nova de Lisboa
}

\begin{abstract}
Resumen:
En los últimos años se está produciendo un creciente interés por el estudio de los victimarios. A diferencia de la víctima, el verdugo no suele testimoniar por voluntad propia, y si lo hace normalmente es para exonerarse de responsabilidad. Esta actitud plantea el problema de la voz enunciativa del victimario. Este artículo propone que la tarea de conocer acerca la identidad del perpetrador perfila un terreno para el intercambio entre la reflexión y la imaginación: el esbozo interdisciplinar de una antropología del verdugo. A través del tratamiento de este asunto en Las benévolas de Jonathan Littell, el texto muestra un ejemplo de cómo la literatura de ficción ofrece un marco para reflexionar acerca de las motivaciones de los perpetradores a partir de su actitud ante el testimonio. El objetivo último del artículo es no obstante señalar las dificultades que rodean la comprensión de los victimarios en el caso concreto de la guerra española de 1936-39 y sus secuelas. La reflexión sobre este asunto lleva a concluir que los problemas de conocimiento del perpetrador están menos en el objeto de estudio que en el propio observador.
\end{abstract}

Palabras clave: victimarios, víctimas, epistemología, valoración moral, teoría de la identidad, reconocimiento, Guerra Civil española, represión, Jonathan Littell, Léon Degrelle, Ernesto Giménez Caballero

\begin{abstract}
:
There is a growing interest in the study of perpetrators. As opposed to victims, victimizers tend not to be willing to testify, and when they do they exonerate themselves from responsibility. This attitude poses the issue of the voice of the perpetrator. This article claims that the task of knowing about the identity of the victimizer offers a terrain for exchanges between reflection and imagination: the interdisciplinary outline of an anthropology of the perpetrator. Through the approach to this issue in The Kindly Ones by Jonathan Littell, the text shows an example of how fiction offers a framework for reflecting on the rationale of perpetrators by focusing on their attitude towards testimony. The final goal of the article is nevertheless to point out the difficulties surrounding the understanding of the victimizers in the case of the Spanish 1936-39 war and its sequels. Reflection on this issue leads to conclude that problems in the knowledge about the perpetrator are less in the object of study and rather more in the observer.
\end{abstract}

Keywords: victimizers, victims, epistemology, moral evaluation, identity theory, recognition, Spanish Civil War, repression, Jonathan Littell, Léon Degrelle, Ernesto Giménez Caballero 
Vivo, hago lo que es factible, eso es lo que hace todo el mundo, soy un hombre como los demás, soy un hombre como vosotros. ¡Venga, si os digo que soy como vosotros! (Littell, Benévolas 26)

Sin reconocimiento no es posible asegurarse una identidad (Pizzorno 36-41), y sin ella tampoco dotarse de un "espacio moral" (Taylor 49-86) con el que dar sentido a la vida y compartirla en colectividad. Una máxima tan sencilla como esta tiene enormes consecuencias para los humanos, que vivimos en comunidad. Para todos: también para los perpetradores de crímenes contra la humanidad, que no dejan de ser humanos, por mucho que sus actos produzcan a una inmensa mayoría una mezcla de repugnancia y extrañeza. Los victimarios, el conocimiento de sus actos, y la relevancia que para esto tienen las reacciones que provocan, son el centro de atención de este artículo, que no aspira a ofrecer sino una primera aproximación a un tema de enorme complejidad y que seguramente va a suscitar atención en los próximos años dentro y fuera del mundo académico. Hablo de la cuestión de la racionalidad subyacente a los actos de los perpetradores de masacres contra población inerme: qué motiva a los victimarios y cómo hacer sus motivaciones comprensibles es una cuestión que desborda las posibilidades de estas páginas; aquí se propone abordar el asunto desde el punto de vista de la identidad, la del perpetrador, pero asimismo necesariamente también la de su observador.

En los últimos años se ha producido un creciente interés por el estudio de los victimarios. La tendencia parece relacionarse, de un lado, con la convención que proclama que, tras la caída del Muro de Berlín en 1989, nos encontramos en un contexto político definible como postotalitario (Linz y Stepan 293), algo que en principio favorece un distanciamiento respecto de los sistemas que se asume que han fomentado formas de exclusión exterminista —a pesar de que el estudio socio-histórico comparado más completo sobre masacres de civiles en estados nacionales en construcción lo que ha establecido es ante todo una relación estrecha entre limpieza étnica y auge de la democracia (Mann 2-5)_; y del otro lado tiene que ver con la dinámica interna de los estudios sobre violencia, especialmente los llamados Genocide Studies, los cuales han ido acusando una saturación del paradigma de la víctima/testigo que se busca compensar con un renovado énfasis en la figura del perpetrador. Con este 'giro' hacia el victimario llegan sin embargo nuevos desafíos teóricos y epistemológicos.

A diferencia de la víctima, y a menudo en franco contraste con ella, el verdugo no suele testimoniar por voluntad propia, y cuando lo hace normalmente es para exonerarse de responsabilidad en los sucesos que se le imputan. Su postura habitual es esencialmente negacionista: aquello no sucedió, o no sucedió como se viene relatando, y además el supuesto victimario no tuvo una implicación en los hechos más que indirecta, delegada o pasiva. Esta actitud no solo acarrea problemas de carácter metodológico, pues obliga a desplegar una hermenéutica sofisticada - para identificar contradicciones internas en su discurso, incongruencias entre este y las evidencias, e incluso atribuir significado a sus silencios-, sino que deja planteada la cuestión de la voz enunciativa misma. En el caso de que testifique, ¿desde dónde, en términos morales, habla el perpetrador, y a qué conjunto de referentes y valores se puede adscribir su discurso? En el caso de que opte por el silencio, ¿cómo ponerle voz, y qué voz poner a quien se niega a hablar?

Lo que este artículo plantea es que la tarea de conocer acerca la identidad del perpetrador compete a la teoría social y la historia pero asimismo a la literatura, perfilando 
un terreno para el intercambio fructífero entre la reflexión y la imaginación: en todos estos géneros y disciplinas el observador se enfrenta a la necesidad de construir una voz con capacidad enunciativa, y en suma de delinear una antropología del verdugo. A través del tratamiento de este asunto en una obra de ficción — Las benévolas de Jonathan Littell—, que relata en primera persona el exterminio perpetrado en Europa del Este por los nazis durante la invasión de la Unión Soviética, muestro un ejemplo de cómo la literatura de ficción ofrece un marco para reflexionar acerca de las motivaciones de los perpetradores a partir de su actitud ante el testimonio. Como plantearé, detrás del silencio o la negación del victimario late una tensión por testimoniar como única vía para recuperar la sensación de pertenencia a la comunidad de los humanos, y este dilema identitario permite fundar una hermenéutica valiosa para un programa de investigación constructivista acerca de la identidad del perpetrador.

El objetivo último del texto es señalar las dificultades que rodean la comprensión de los victimarios en el caso concreto de la Guerra española de 1936-39 y sus secuelas. Para los perpetradores del bando franquista el dilema entre testimoniar o no hacerlo no refleja una tensión moral comparable a la de otros casos de grandes victimarios de crímenes contra la humanidad. A través de dos testimonios producidos, uno durante la dictadura y el otro durante la transición a la democracia, planteo que este tipo de perpetradores no expresa que su identidad esté en riesgo al testimoniar, y trato de dar una explicación a este fenómeno que ilustra cómo los literatos o intelectuales funcionan en la cultura española moderna como una comunidad auto-referencial que viene desde la transición reproduciendo las condiciones semánticas para la impunidad de los crímenes del franquismo. Finalmente concluyo con unas reflexiones acerca de cómo los problemas de conocimiento del perpetrador están menos en el objeto de estudio que en el propio observador.

\section{E1 'giro' victimario, entre la teoría social y la experimentación literaria sobre los modos enunciativos del perpetrador}

[A] decir verdad, el suicido no me tienta gran cosa [...] Y en tal caso, como forma de emplear los ratos perdidos, escribir es una ocupación tan buena como otra cualquiera. (Littell, Benévolas 10)

2017 seguramente pasará a la historia de la historiografía como el año de la puesta de largo de lo que se conoce ya como el 'giro' victimario. El fenómeno tiene de momento por epicentro una red de investigadores coordinada desde la Universidad de Utrecht cuya página web centraliza proyectos, conferencias y publicaciones, además de vínculos con otras actividades relacionadas con los Genocide Studies (https://perpetratorstudies.sites.uu.nl/). Cuenta no obstante con avales de relevancia: este mismo año ha visto la luz un estudio con el título expreso de Perpetrators, cuyo autor plantea que solo "a full account of the horrors and cruelties" de la Shoah "enables us to address the issue of individual participation" (Lewy ix), ampliando así enormemente los objetivos y exigencias de un campo de investigación en ciernes; y para fines de este mismo 2017 se anuncia la publicación de un promisorio Journal of Perpetrators Studies. Por su parte desde Francia se está reclamando también una nueva historia cultural del nazismo que, más allá de la reconstrucción de "la logistique" que ha presidido hasta el momento el estudio 
de su maquinaria exterminista, se adentre en la comprensión de "la logique des criminels, cet univers mental si particulier" del que procedían los presupuestos, los planes y las relaciones que hicieron posible el Lager concentracionario (Chapoutot 19).

No puede decirse que con este 'giro' hacia el victimario estemos ante una novedad o una originalidad; de hecho su pretensión es tan antigua como la conciencia misma del genocidio. La apuesta por hacer comprensible la racionalidad del verdugo como vía hacia el conocimiento del mal exterminista está ya insinuada por Primo Levi en un pasaje de su crónica de 1947 sobre su paso por Auschwitz durante la guerra mundial (Chapoutot 11-13). En ella Levi, que había conseguido preservar la vida en el campo de concentración gracias a sus conocimientos de química orgánica, se enfrenta en una ocasión a un examen que, de no pasarlo satisfactoriamente, puede llevarle a la cámara de gas. El examinador — profesor Pannwitz- por mucho que tenga que reconocer su valía, trata al examinando como si no fuese un humano: según el prisionero, cuando se cruzan sus miradas, aquel tipo bien vestido, "alto, delgado, rubio" y con plena conciencia de ario seguramente estaba pensando que "[e]sto que hay ante mí pertenece a un género al que es obviamente indicado suprimir" (Levi, Si esto es un hombre 112). La anécdota quedó grabada en la memoria de Levi, quien dice haberse preguntado muchas veces después "cuál sería su funcionamiento íntimo de hombre"; y, asumiendo que "aquella mirada no se cruzó entre dos hombres", declara:

si yo supiese explicar a fondo la naturaleza de aquella mirada, intercambiada como a través de la pared de vidrio de un acuario entre dos seres que viven en medios diferentes, habría explicado también la esencia de la gran locura de la tercera Alemania. (Levi, Si esto es un hombre 113)

En la práctica, no obstante, los estudios sobre la figura del perpetrador han estado fundados en una prevención moral que solo aconseja ahondar en la racionalidad del victimario en la medida en que contribuya a dignificar a las víctimas. Entre las aproximaciones disponibles quizá la más seminal es la noción de "banalidad del mal", acuñada por Hannah Arendt tras su seguimiento del juicio sumario contra Adolf Eichmann, un alto oficial de las SS directamente encargado de hacer ejecutar la 'Solución Final'. La reflexión de Arendt ha dado lugar a una desbordante literatura reflexiva desde la filosofía moral —especialmente sobre la posibilidad de instituir hasta la rutinización un mal absoluto-, pero asimismo a aplicaciones en la historiografía (Browning; Goldhagen; Welzer) y la sociología (Sémelin) en estudios que subrayan cómo 'hombres normales' sin patologías psicológicas reseñables pueden terminar convertidos en activos verdugos. Con todo, y pese a esta aparente utilidad, Arendt estaba interesada en la evaluación moral del perpetrador y no en profundizar en la racionalidad de sus actos - que en su enfoque son calificados de producto de una perversión del ideal kantiano del imperativo categórico- o en su discurso, que resumió como un "conjunto de frases hechas y clichés autoinventados" referidos a un "lenguaje burocrático" (Arendt 136). Su perfil de Eichmann, por sugerente que haya sido considerado, queda cuando menos incompleto, en parte además porque no asistió a todo el proceso judicial: no estuvo presente durante el testimonio que el acusado aportó como defensa (Cesarani 197), lo cual ayuda a entender que perfilase un retrato que no subraya la profunda identidad antisemita de Eichmann, constatable por otras evidencias, dejando además sin abordar la relación entre el testimonio y la identidad del victimario. 
Su principal alternativa ha sido la noción de "zona gris", originariamente planteada por Primo Levi como un espacio "de contornos mal definidos" que "separa y une al mismo tiempo" a "patrones y siervos", los dos sujetos que configuran el orden concentracionario (Levi, Hundidos 18). Según Levi la 'zona gris', al desdibujar las figuras del amigo y el enemigo, deja en suspenso en quién depositar la confianza para establecer lazos de alianza y fraternidad, dificultando a la víctima orientarse en el Lager. Las dimensiones moral y de conocimiento aparecen así solapadas en este enfoque, que dibuja además un escenario cuya "estructura interna" resulta "extremadamente complicada", pues la maquinaria del exterminio no aspira solo a la destrucción física de los condenados sino ante todo a hacerles perder la dignidad a través de una perversa práctica que culpabiliza a la víctima y fomenta en ella el olvido por haber participado de "la implicación de las víctimas en su propia destrucción” (Galcerà i Padilla 7).

La categoría de 'zona gris' ha servido para hacer comprensible que la racionalidad de la víctima puede ponerse al servicio de la lógica exterminista del victimario (Bauman 171), desdibujando las fronteras entre una y otro y favoreciendo la impotentia iudicandi. Ahora bien, como superviviente a Levi lo que le interesa del conocimiento que puede aportar esta categoría — acuñada para abordar el problema del colaboracionismo entre las víctimas - es contribuir a la memoria del campo de concentración frente al olvido que buscan el revisionismo y el negacionismo. Es esto lo que le mueve a tratar de arrojar luz sobre un fenómeno al que "no le falta ningún elemento para dificultar el juicio", pero ante todo con objeto de "separar el bien del mal" (Levi, Hundidos 18).

En resumen, tanto Arendt como Levi dejaron planteada la cuestión central del 'giro' victimario - ¿cuál es la racionalidad subyacente al perpetrador, capaz de poner en marcha el exterminio y la perversa zona gris?-, pero con sus opciones han contribuido también a poner límites al conocimiento, transmitiendo a los observadores del presente el temor a que la aspiración a dar respuesta a esta cuestión entre en conflicto con la postura moral innegociable de rechazo a los verdugos. Esta tensión sigue marcando los primeros pasos del 'giro' victimario, cuya hoja de ruta, partiendo del reconocimiento del declive de la figura de la víctima como encarnación incuestionable de la memoria, plantea tratar de navegar entre la Escila de "the desire and need to understand the motivations behind these people's actions" y el Caribdis de "the ethical imperative not to try to understand, because understanding might imply forgiveness" (https://perpetratorstudies.sites.uu.nl/). Ante una disyuntiva tan radical, las proclamas a favor de la interdisciplinariedad - la nueva línea convoca a expertos en historia, criminología, derecho, estudios forenses, estudios culturales, sociología, antropología, filosofía, estudios sobre memoria, psicología, ciencia política, literatura y educaciónse muestran de escasa utilidad.

Para asegurar el éxito de esa invocación a la concurrencia de disciplinas, antes debe reducirse la distancia o el disenso entre lo moral y lo epistemológico. Una manera de avanzar en esa dirección es a través del intercambio entre imaginación y reflexión teórica, es decir, poniendo a colaborar a la literatura con la teoría social y la historia. La opción es epistemológicamente legítima, pues de un lado toda reconstrucción de la lógica del victimario ha de adoptar por necesidad la forma de una narración en la que este justifique de alguna manera su relación con los hechos que se le atribuyen. Y de otro, en tanto que narrador, el verdugo ha de dirigirse a una audiencia para validar su discurso. De cara al estudio del testimonio del victimario, la dimensión literaria y la sociológica conforman en suma el marco en el que se manifiesta la tensión entre lo 
valorativo y lo cognoscitivo, lo que permite tratar de someterla a un cierto control analítico, indispensable para dar pie a una investigación histórica.

En efecto, en última instancia el narrador debe con su discurso referir a algún "círculo de reconocimiento" del que depende su identidad en el tiempo (Pizzorno 3642); por su parte, para hacer la narración compresible, victimario y círculo han de compartir los significados esenciales de las palabras y conceptos empleados. Sobre esta base, si el victimario ofrece una narración acorde con los valores de un círculo de reconocimiento postexterminista, con su discurso estará expresando que abjura de sus actos criminales: el formato que adoptará su discurso será entonces alguna forma de confesión o arrepentimiento, solicitando del público un juicio absolvedor, aunque a escala narrativa el precio será deformar el sentido originario de sus actos. Si no confiesa, en cambio, es porque considera que su identidad está sustentada por otro círculo de reconocimiento, vinculado este a valores propios del contexto de perpetración de los crímenes pero que sigue constituyendo su comunidad referencial. En suma, el victimario tiende a no testimoniar cuando mantiene un vínculo identitario con un círculo de reconocimiento propio del contexto de los hechos; es solo que, dado que este carece ya de legitimidad, no se puede dirigir a él públicamente. El compromiso moral con dicha comunidad se expresa así en un silencio con medio del cual, por otro lado, aspira a preservar el significado originario de sus motivaciones. Ahora bien, en un contexto postexterminista, no es solo que dicho círculo haya perdido la posición hegemónica sino que además sus miembros pueden entretanto haber desaparecido (en términos biológicos o identitarios), y esto abre la posibilidad de la anomia, es decir, la pérdida de referentes para el victimario, cuya salida extrema podría llegar a ser el suicidio. Lo habitual, no obstante, es que los círculos heredados experimenten cambios más bien progresivos que drásticos en sus referentes morales, y que por su parte el perpetrador se beneficie de su implicación en varios círculos, viejos y nuevos (y reales o imaginarios), lo que le permitirá combinar distintos discursos — que suelen ir del recuerdo activo en privado a la negación en público— - sin menoscabo de su sensación de pertenencia e identidad.

Podemos denominar todo este escenario el 'dilema del perpetrador', el cual tiene que ver, según planteo, con una tensión entre círculos de reconocimiento, y que a su vez también argumento que regula el formato del discurso perpetrador y en conjunto la posibilidad y la factura de la voz enunciadora. Es en este punto donde, para visibilizar dicha tensión y ofrecer un mapa de las opciones discursivas que se abren al victimario, la literatura puede venir en apoyo de la teoría social y la investigación histórica, si bien a cambio de ello la construcción pasa entonces a primar sobre la reconstrucción. Esta opción es de hecho la que parece haber fundado la estrategia narrativa de Jonathan Littell en su premiada novela Las benévolas de 2006.

Littel sorprendió al público y se ganó el reconocimiento de la crítica con una novela en la que pone en boca de un alto oficial de las SS inventado - Maximilian Auelas atrocidades cometidas por los nazis durante la Operación Barbarroja sobre Ucrania y en dirección a Stalingrado. La obra suscitó desde temprano reacciones totalmente contrarias, desde el ensalzamiento por parte de Jorge Semprún —que anticipó en ella la referencia futura sobre el exterminio judío- a la censura abierta de Julia Kristeva, quien se esforzó por presentarla como peligrosamente orientada a "restitue l'univers d'un criminel" (Clement 2). Esta última postura es en sí misma señal de la virtual au- 
sencia en la esfera pública de testimonios sobre masacres y crímenes contra la humanidad del lado de los victimarios, y ello vuelve ya de por sí relevante la obra de Littell como posible contribución al conocimiento sobre las motivaciones de los victimarios. Las polémicas que desde su publicación acompañaron el libro se centraron en discutir si el testigo ideal o deseable del Holocausto debía ser el perpetrador, y en cuestionar que la novela fuese otra cosa que una obra de ficción sin valor histórico (Devarrieux y Levisallies). Ahora bien, nadie ha puesto en duda el rigor de Littell en el conocimiento detallado del funcionamiento de las instituciones exterministas, los conflictos jurisdiccionales entre organizaciones y los planes para los Untermenschen: en definitiva, su conocimiento sobre la cultura de los verdugos de los judíos centroeuropeos y otras minorías. Por tanto, y al margen de que la trama de la novela contenga también notables licencias como es esperable en una obra de ficción, la voz enunciativa que adopta el autor merece ser tomada en consideración dentro del 'giro' hacia el perpetrador.

La voz de Aue protagoniza la introducción del libro, en la que el autor presenta el testimonio elaborado por un protagonista que declara sin ambages: "No estoy arrepentido de nada; hice el trabajo que tenía que hacer, y ya está" (Littell, Benévolas 12). Esta postura de Aue aleja su voz en primera persona de la de un sujeto cuya identidad depende del reconocimiento de un círculo fundamentado en los derechos humanos. Aue subraya aún más su posición: "gracias a Dios, nunca he necesitado, como mis ex colegas, escribir mis memorias para justificarme, porque no tengo nada que justificar". De paso despeja otros posibles orígenes espurios para el testimonio extendidos entre antiguos nazis, como la necesidad económica: "tampoco tengo intenciones lucrativas, porque me gano la vida bastante bien con lo que hago".

Desde la teoría de la identidad como reconocimiento, la postura de Aue expresaría en principio un típico dilema del perpetrador: si se niega a testificar por lealtad a unos valores que le vinculan con un círculo de reconocimiento propio de la experiencia exterminista corre el riesgo de caer en la pérdida de referentes y la anomia, pues por su manera de exponer que carece de remordimientos o necesidades deja claro que ha roto los vínculos con sus antiguos correligionarios nazis. Sin embargo, el protagonista de Las benévolas tampoco contempla el suicidio, según aclara en el textual que abre este epígrafe. En principio solo le quedaría entonces como opción un testimonio negacionista; pero esto es justamente lo que no ofrece: al contrario, lo que Aue hace a continuación es conducir al lector por los horrores de las matanzas de judíos en los que se vio implicado de manera activa, aunque lo haga desde una opinión contraria al exterminio y a favor de la esclavización de los Untermenschen, por la que no obstante tampoco lucha activamente.

¿A qué racionalidad responde, en suma, el testimonio de este perpetrador? Es en este punto donde la ficción y sus reglas permiten ir más allá de los límites que impone el afán reconstructivo de las ciencias sociales y humanas, aportando toda una dimensión que, aunque originada en la imaginación, deviene valiosa para el conocimiento. Pues en la medida en que el autor necesita diseñar un protagonista dispuesto a testimoniar —única forma de elaborar una novela en primera persona-, se ve obligado a reflexionar sobre alguna justificación que pueda quedar para el victimario que ni se arrepiente ni está dispuesto a callar. La que plantea Jonathan Littell es por referencia a una estética: el placer de transmitir una historia bien contada, lo que viene a reflejar el valor dado a la literatura en una sociedad moderna. 
Podría parecer que en el mejor de los casos esta justificación aleja la estrategia de Littell de toda dimensión de conocimiento, por no hablar de que sería de nulo interés para la teoría social o la filosofía moral. En realidad la apariencia engaña, pues con esa justificación aparentemente diletante y esteticista el protagonista no deja de apelar a un público, sin duda a uno algo diferente del círculo de reconocimiento fundamentado en los derechos humanos, pero por ser más amplio y universal: el público lector en su totalidad. Desde ese momento, al igual que a cualquier otro sujeto respecto a su círculo, a la voz enunciativa de la novela le es aplicable la teoría de la identidad como reconocimiento.

En efecto, al enunciar su justificación literaria aparentemente ociosa e irresponsable, Aue se está dirigiendo a un destinatario; y además no de modo desinteresado como en principio reclamaría el lema áureo de la literatura como 'arte por el arte': pues a continuación la vOz del protagonista intenta seducir al lector, arguyendo que el relato que puede ofrecer "no es algo ajeno a vosotros" los lectores universales (Littell, Benévolas 7). Sin duda pretende así presentar sus actos criminales como potencialmente propios de cualquier ser humano. Sabemos, no obstante, que nadie puede garantizar una estrategia maximizadora en cuestiones de identidad, ya que esta depende en última instancia del reconocimiento que se reciba de otros. Visto así, es en realidad Aue quien, al ofrecer su relato, pasa a depender de la valoración que de sus actos pasados haga esa comunidad compuesta por los lectores actuales. Pero hay más, porque el hecho mismo de ofrecer una narración es expresión de una búsqueda de reconocimiento, sin el cual elaborar aquella carecería de sentido. Detrás de la justificación estética hay en fin una apelación moral a una comunidad, lo que compromete al narrador: el testimonio de Aue, por mucho que venga racionalizado desde la estética, no deja de estar sujeto a la lógica de la "responsabilidad ante el otro" que configura todo relato autobiográfico mínimamente introspectivo, máxime en el caso de un superviviente - algo que el victimario no deja formalmente de ser- el cual, cuando testifica, lo hace en última instancia por todos aquellos que no sobrevivieron (Loureiro, Huellas 19-41).

La novela se abre por eso con una sentencia cargada de significación: "Hermanos hombres, dejadme que os cuente cómo ocurrió" (Littell, Benévolas 7). Ese pasaje inicial y otras reiteraciones del estilo en la introducción de Las benévolas han sido objeto de tratamiento desde la teoría literaria, encontrando en ella resonancias propias de la tragedia clásica (Trubetzkoy); se ha dicho también que el autor no hace sino parodiar el formato enunciativo de los testimonios de supervivientes, que también suelen incluir invocaciones a la humanidad entera (Murat). Ahora bien, la apelación fraternal de Aue, por falsa y oportunista que pueda sonar, expresa la aceptación por el victimario de los referentes valorativos de la modernidad civil, precisamente aquella que el nazismo trató de subvertir en nombre de una ideología de la desigualdad entre humanos. El verdugo viene así a conceder una derrota que no es ya política sino también moral, identitaria.

Más allá de esto, para poner voz a un perpetrador a la vez impenitente y locuaz, Littell está sintetizando todo el repertorio de opciones que definen el dilema del perpetrador. Permite así comprobar que la única alternativa al riesgo de anomia es para cualquier sujeto la búsqueda de reconocimiento en alguna comunidad de referentes morales, sea esta nueva o heredada, circunscrita o universal, pues solo ella asegura una identidad; también al perpetrador. Y esto a su vez ayuda a delimitar sociológica e históricamente la disyuntiva entre lo epistemológico y lo moral: independientemente del 
juicio que merezcan sus actos, detrás de la actitud del victimario hay una tensión entre círculos de reconocimiento que le garanticen un espacio moral.

\section{La democracia posfranquista y el (re)conocimiento del perpetrador}

Sería totalmente incapaz de salir de esa tranquilidad terrible, aunque lo quisiera. (Littell, Benévolas 9)

Hasta aquí he abordado la cuestión de cómo contribuir al conocimiento de la identidad de los verdugos de crímenes contra la humanidad a través de una combinación de reconstrucción y construcción de la voz del perpetrador; y para ello he escogido un ejemplo que da voz a un victimario a la vez sin remordimiento y locuaz, pero tomado de la ficción. Sin embargo, estos sujetos, aunque en principio escasean, se encuentran en la realidad histórica y a nuestro alrededor. El propio Littell ha trabajado uno de ellos, lo que nos permite de paso acercarnos a España.

España es un caso extraño dentro del mapa de los crímenes contra la humanidad: no figura en el ranking de los genocidios del siglo XX, pero el uso de este término se encuentra cada vez más naturalizado cuando se hace referencia a la dimensión represiva de la guerra de 1936-39; incluso ha dejado de ser un tabú entre los historiadores, y empieza a ser empleado como categoría heurística para dar significado a las matanzas de civiles perpetradas por los seguidores de Franco (Míguez Macho 23-26). Por otro lado, desde comienzos del siglo XXI España ha asistido al igual que tantos otros países al auge del paradigma de la víctima, lo que ha dado lugar ya a voces críticas que señalan que convertir la memoria en "el repositorio de la verdad" no hace sino poner sobre la mesa la cuestión de acerca de quién o para quién es dicha verdad (Loureiro, "Pathetic Arguments" 226), o que sugieren que una víctima que empieza a estar "en todas partes" (Gatti y Martínez 8) amenaza con solaparse con la que en origen era su figura antagónica, el ciudadano. Tal vez por eso también en España avanza el paradigma victimario, para empezar en la literatura (Lauge Hansen), pero incluso ya en algunos estudios académicos que se interesan por analizar las dificultades de lograr que los verdugos de la represión franquista ofrezcan testimonios en lugar de mantenerse en el silencio o la negación. En efecto, tal y como Payne y Aguilar constatan, también en España las voces de los verdugos son en general "few, fleeting, and fugitive" (Payne y Aguilar 43). Pero esto no quiere decir que la antropología del victimario sea en el caso español equiparable a la de cualquier otra encrucijada exterminista.

De cara a señalar analogías y diferencias, de nuevo aquí la sinergia entre literatura, ciencias sociales e investigación histórica es garantía de un mejor abordaje. Al hilo de la redacción de su novela y como parte del cuidado trabajo previo de documentación y reflexión, Jonathan Littell elaboró un ensayo que a su vez se inspira en el pionero estudio de Klaus Theweleit sobre la mentalidad de los miembros de las Freikorps alemanas, tropas de voluntarios excombatientes que se dedicaron a la represión de los movimientos políticos revolucionarios al término de la Primera Guerra Mundial y durante los primeros años de la República de Weimar. Theweleit planteó cómo la producción de deseo puede consistir en "death production" (Ehrenreich xiii), al punto que la masacre de civiles no constituya un medio para otros fines sino un fin en sí mismo, por medio del cual el criminal "is doing what he wants to do" (xi). A partir de 
cartas y otros testimonios de estos machos-soldados y basándose en Guattari y Deleuze, Theweleit sitúa la conformación de esta identidad exterminista en un estadio pre-edípico de odio-temor a la alteridad de género - y a las mujeres de manera muy concreta- como posible amenaza de disolución de la identidad propia, que a su vez el autor extiende al comunismo emancipatorio y a la clase obrera con conciencia, en lo que no es tanto un paso de lo micro a lo macro cuanto un mecanismo que reúne desde lo libidinal a lo ideológico en nombre de la conservación del ego como pulsión experimentada a vida o muerte. La metaforología desentrañada por Theweleit — que imagina la temible fuerza de lo femenino como una suerte de marea que lo engulle y disuelve todo a su paso - sirve a Littell de guía para abordar una dimensión ulterior de esa fantasía ero-exterminista en la necesidad de los nazis de luchar "[c]ontra todo cuanto fluye", frente a lo cual han de "instaurar todo cuanto esté erecto" (Littell, Lo seco 35), en una guerra sin cuartel que se revela en última instancia inútil, pues lo fluido resulta imparable y desbordante.

Es bastante razonable pensar que el personaje de Maximilian Aue - cuyas fantasías sexuales y pesadillas sobre lo viscoso atraviesan la novela- está inspirado en el estudio que Littell lleva a cabo en Lo seco y lo búmedo. Pero el interés por este ensayo en estas páginas no se debe a su abordaje del fascismo desde una metaforología complementaria que ilumina otros referentes de la identidad del perpetrador. La obra es interesante también de una manera muy directa y específica al contexto español de la posguerra, contemporáneo de la experiencia de conquista y destrucción nazi en el Este de Europa. Pues Littell centra su ensayo en la producción de un perpetrador que pudo desarrollar una escritura autobiográfica gracias a la cobertura que le proporcionó el régimen de Franco una vez destruido el III Reich. Se trata de Léon Degrelle, el líder de la organización fascista de Bélgica Christus Rex durante los años treinta y que, tras presentarse voluntario para la campaña alemana en Rusia en 1941 e integrarse en la llamada 'Legión Valonia' reservada a extranjeros, fue escalando posiciones en las Waffen SS y recibiendo reconocimientos y galardones, el último de ellos entregado por el propio Fübrer Adolf Hitler en los días finales de la guerra (Bruyne y Rikmenspooel 12 28). La peripecia de Degrelle ante la debacle nazi en 1945 terminó con una huida desesperada desde Noruega en un avión que, falto de combustible, logró hacer un aterrizaje de emergencia en la bahía de San Sebastián. Desde entonces y con el visto bueno de las autoridades franquistas residió en España — primero como fugitivo, después como desaparecido oficial y finalmente como español nacionalizado- donde se dedicó a escribir obras de exaltación mitificadora sobre su implicación en la Operación Barbarroja, empezando por La campaña de Rusia (1949) en cuyo lenguaje se centra el ensayo de Littell.

A diferencia de tantos otros nazis supervivientes, Degrelle sí testimonió, y de modo voluntario. Para ello tuvo necesariamente que contar con un contexto en el que el lenguaje disponible no se hallaba en discontinuidad semántica con el que había justificado su implicación en la salvaje represión que acompañó la apertura por los alemanes del frente ruso. Si Degrelle pudo verbalizar su testimonio no fue en fin solo porque contase con el amparo institucional del régimen franquista, sino porque además existía una audiencia potencial que avalaba su relato impenitente, sobre todo dentro de España aunque con el tiempo también fuera - entre viejos nazis y fascistas sobrevividos, y con el tiempo nuevos públicos de extrema derecha- de manera que podía mantener la factura originaria de su discurso sin resultar incomprensible. No se enfrentó pues al 
dilema del perpetrador, al contar con un círculo de reconocimiento que no había variado drásticamente sus referentes identitarios anteriores a 1939-45 ni soportaba valores crecientemente contrarios a los del orden que diseñó y ejecutó los planes exterministas de los que Degrelle, en tanto que mando de las SS, indirectamente participó.

Esta interpretación sobre la función del franquismo, no en cuanto régimen político sino como contexto socio-cultural amparador del testimonio de un victimario tiene un límite, no obstante: pues al fin y al cabo Degrelle no participó en la guerra de 19361939 en cuyo escenario se fraguó el lenguaje referencial de su público potencial. Se trata además de un extranjero que escribió sus libros en francés, los cuales solo con el tiempo fueron traducidos al castellano — sus Memorias de un fascista son de 1975 y tienen por título original Hitler pour mille ans (1969)_, de manera que no puede ser el tipo de testigo clave para ilustrar el argumento de que en la España de Franco proliferasen testimonios a la vez impenitentes y locuaces como el que Littell propone a través del personaje de Aue.

Pero los hay. Uno de ellos puede ser visto en acción en una entrevista concedida al diario El País en 1979 con motivo de la publicación de su autobiografía Memorias de un dictador. Ernesto Giménez Caballero, el que fuera ideólogo de la extrema derecha durante la República e impulsor del aparato de propaganda del bando franquista en los primeros meses de la guerra, no muestra en ella una brizna, no ya de contrición sino siquiera de pesadumbre por los efectos que sus ambiciones ideológicas comportaron para los derrotados en la contienda: "Yo no me arrepiento de nada", espeta (Marín). Hace esta afirmación además a continuación de distanciarse abiertamente de sus antiguos correligionarios, los "intelectuales del Movimiento", quienes en su parecer "al llegar la democracia, procuraron borrar su pasado, en lugar de justificarlo honestamente".

Ya solo por esta postura, la elección de Giménez Caballero resulta adecuada como ejemplo de testimonio de un perpetrador no arrepentido ni mudo. Además de por esto, su más notoria obra — Genio de España (1935) - en la que anticipa la llegada de un caudillo que acabe con la postración espiritual de la nación imperial española, contiene elementos del tipo de pulsión originado en el temor a la "castración desmembradora" identificada por Theweleit y Littell en sus ensayos sobre el imaginario exterminista (Labanyi 381). Pero sobre todo, la manera en que Giménez Caballero se autoexculpa emparenta de modo directo con la opción imaginada para el protagonista de Las benévolas: se exonera de toda responsabilidad presentándose como un esteta, un escritor y pensador solo interesado en el arte y su potencialidad de regeneración cultural y espiritual. Se explicaría así además su capacidad de ofrecer un discurso careciendo como parece a la altura de finales de los años setenta de un círculo de reconocimiento heredado aunque a la vez enajenándose respecto del que se iba volviendo hegemónico con la transición a la democracia, lo cual convierte la apuesta imaginativa de Littell en una verdadera hipótesis teórica susceptible de comprobación empírica en casos reales. De la construcción volvemos así a la reconstrucción.

Hay no obstante una diferencia crucial entre la manera en que Littell experimenta con la justificación estética en su personaje de ficción y el modo en que parece haberla vivido Ernesto Giménez Caballero. Pues con su testimonio formalmente artístico Max Aue busca abiertamente el reconocimiento de una comunidad de lectores potenciales identificable con la humanidad entera, mientras que Giménez Caballero, pese a toda su dedicación a la creación literaria y sus fuertes convicciones católicas formalmente 
universalistas, no se dirige en su obra a ningún público amplio esperando su juicio absolvedor: mantiene su discurso en unas coordenadas trascendentalistas que no interpelan a los seres humanos sino que dicen interpretar designios metahistóricos de origen divino.

La otra diferencia con Aue es que, aunque se inscribió voluntario en el ejército franquista como alférez provisional, Giménez Caballero no consta que fuera un exterminista activo. Puede pensarse entonces que la suya fue una implicación con la represión por medio del discurso, y que este al fin y al cabo son solo palabras. Pero lo que anima el ensayo de Littell es justamente el lenguaje (Littell, Lo seco 24-35), que se considera dotado de una capacidad mayor que la de los sistemas políticos o económicos de constituir "a specific form of production of reality" (Theweleit 349). Vista así, la suya es una responsabilidad probablemente sin parangón en la construcción del nuevo Estado franquista y en la destrucción colectiva que este acarreó.

Y sin embargo, Giménez Caballero no figura en absoluto así en los anales. No es solo que las facetas que han sido estudiadas de su trayectoria sean la estética y la ideológica, en "aparente dicotomía" (Hernández Cano 261) y dejando de lado su implicación activa en la maquinaria de deshumanización del enemigo como parte de su lealtad incondicional al régimen de Franco: es también que desde la transición postfranquista aparece caracterizado como un personaje entre políticamente excéntrico e ideológicamente inofensivo, según epitomiza la definición que de él dio Francisco Umbral como "el Groucho Marx del nuevo Estado" franquista (Umbral 60). Esto puede haber sido así a la altura de mediados de los años setenta, pero no en los años cruciales en los que en inspiración de su discurso se cometieron crímenes contra la humanidad.

Si atendemos a la teoría de la identidad aquí expuesta, el reconocimiento estrictamente como autor literario que ha recibido Giménez Caballero desde la muerte de Franco pone en evidencia los valores que dominan en el círculo que en la práctica le ha servido de referente, y único al que el autor se dirigió en su autobiografía. Esta no es, como hemos visto, una comunidad de lectores tanto como de literatos, y que ahora queda retratada también como grupo que funciona de espaldas al público y que viene desplegando una particular manera de banalización del mal. La conclusión, bastante desoladora es, por resumirlo, que personajes como Giménez Caballero no figuran en la esfera pública de la democracia posfranquista en tanto que victimarios, y ello se debe a la naturalización de que han sido objeto los vencedores de la guerra de 1936 por parte de la comunidad cultural hegemónica surgida de la transición, la cual como sabemos constituye una potente maquinaria de inclusión y exclusión (Martínez 17-21).

Las Benévolas ha sido criticada por la efectista frialdad del protagonista, pero en realidad ello es parte de la estrategia con que el autor busca dar coherencia a la antropología del verdugo. Lo que Littell plantea, en consonancia con la teoría de la identidad como reconocimiento, es que estas personas no pueden salir del estado de frialdad que acompaña la deshumanización activa que hacen de sus víctimas. Al igual que Aue, Giménez Caballero figura entre los perpetradores que no pueden superar "esa tranquilidad terrible" porque no sienten ninguna culpa pero a la vez están atrapados en los efectos morales de esa actitud. Y es que hay una moral detrás de la estética: la hay en Aue, la hay en Degrelle, la hay en Giménez Caballero. Una moral exterminista, por cierto, cuyo efecto es la deshumanización, pero no solo del otro sino también del yo que deshumaniza al otro. 
Este retrato moral no vale para todos los perpetradores, no obstante; solo para los impenitentes y locuaces. Una manera final de remachar esta perspectiva es ofreciendo una comparación entre la actitud de sujetos como Giménez Caballero y la de otros implicados de manera directa o indirecta en masacres de civiles durante la guerra de 1936 que pueden aspirar a figurar como crímenes contra la humanidad. Un ejemplo bien reseñado durante la transición en el campo de la literatura —más concretamente en un género en el que se entrecruzan la ficción, la memoria y la historia- es el de Dolores Ibárruri en el magistral recuento de Jorge Semprún a su llegada del exilio:

Pasionaria, sin duda, morirá sin decir nada. No ha vuelto a España para hablar, para decir las verdades sangrientas y miserables del pasado. (Semprún 122)

El silencio de personajes como Pasionaria permite aventurar que en la democracia posfranquista hay heredadas de la transición dos posturas diferentes entre victimarios, dependiendo de si son del lado de los vencedores o de los vencidos: solo la segunda adopta en general el silencio como postura ante los reclamos de testimoniar, lo cual señala una vinculación moral con un círculo de reconocimiento heredado o virtual que se considera aún valioso para el testigo, y que remite al contexto en el que se produjeron los hechos.

Ahora bien, en este caso de los victimarios de la izquierda estamos topando con la paradoja de un sujeto que calla habiendo obtenido reconocimiento, como es el caso de exiliados que retornaron como Dolores Ibárruri entre otros: su postura ante el testimonio solo es posible si el reconocimiento que se recibe es precisamente por practicar y favorecer el olvido, y esto a su vez indica que existe una audiencia que da valor a este tipo de referentes.

Pero la encrucijada de los primeros es más aterradora. No se caracteriza por el silencio sino por la articulación de un discurso que tampoco es negacionista sino que se mantiene leal al contexto de origen de los actos, solo que su actitud es presentada en un lenguaje estético que, como hemos visto, funciona como un mecanismo de exoneración de responsabilidad, y en última instancia de impunidad. De esa doble armazón de silencios fomentados y locuacidades irresponsables está hecha la matriz cultural de la democracia que continúa hoy en España.

\section{Conclusión: victimarios, identidad y los límites morales del observador}

Hermanos hombres, dejadme que os cuente cómo ocurrió. No somos hermanos tuyos, me replicaréis, y nos importa un bledo [lo que nos quieres contar]. (Littell, Benévolas 7)

No está claro que exista una condición humana, menos un parámetro de medida de 'lo humano', pero lo que es cierto es que la cultura moderna asume que la humanidad existe y merece el derecho a la vida. El reconocimiento de crímenes contra la humanidad perpetrados por otros humanos es una dura prueba para ese supuesto. Puesto que lo habitual es que el perpetrador, o bien se niegue a ofrecer un testimonio o bien lo haga en unos términos no avalados por la información disponible por documentos u otros testimonios, el conocimiento de las condiciones subjetivas de la participación en 
masacres sobre civiles en situaciones de estado de excepción plantea desafíos al observador.

En este texto he tratado de mostrar que los problemas a los que se enfrenta el literato, el científico social y el historiador son en una cierta medida análogos: en todos los casos, y más allá de ofrecer un relato verosímil y coherente sea a partir de la documentación disponible o desde la imaginación, el observador necesita dotarse de una imagen de la personalidad del perpetrador, es decir, necesita encarar la cuestión de la identidad del victimario. Al abordar conjuntamente en la figura del verdugo los problemas de observación y de valoración moral, la agenda del literato de ficción se adentra necesariamente en el terreno de la del biógrafo, el historiador, el teórico de la identidad y el filósofo moral, pues todos necesitan plantearse qué es lo que se puede legítimamente reclamar a un relato que adopte la mirada del perpetrador; y viceversa, la de estos se aproxima a la del literato, ya que al silencio del perpetrador solo se puede poner voz construyéndola con aportes procedentes de la imaginación. De ahí que hablemos de sinergia entre disciplinas y saberes.

En la medida en que se trata de un asunto que afecta a su identidad, el por qué los victimarios en general no testifican tiene que ver con el reconocimiento que pueden recibir por parte de un orden de valores que repudia y aberra de sus actos. Pero el caso español es específico en este extremo, pues por avatares de su historia contemporánea ha producido un tipo de testigo capaz de no asumir los valores de la cultura de los derechos humanos y a la vez de no mantenerse en silencio, aunque sea para ofrecer un testimonio muy singular cuyas matrices de significado le hacen irresponsable en virtud del aval que recibe de la comunidad a la que siente pertenecer, formada por literatos e intelectuales, unos hombres de letras cuya auto-referencialidad moral en la práctica reproduce la impunidad.

De un modo más general, los tipos antropológico que han sido aquí abordados en relación con España evidencian que no todo lo que no es hegemónico es subalterno. En relación con el discurso dominante, la diferencia entre un subalterno y un victimario es que el primero no puede decir quién es aunque quiera, mientras que el segundo no quiere decir quién es aunque pueda. Se trata de dos situaciones diametralmente contrarias si bien ambas se sitúan en la exterioridad del discurso hegemónico. La perspectiva poscolonial no puede hacerse cargo de ninguno de los dos tipos de discurso que han aparecido en estas páginas: el del victimario que pudiendo hablar se calla, y el del que ofrece una modalidad de relato que, sin ser hegemónica, elude toda referencialidad a su posible responsabilidad moral.

Pero la principal conclusión de este texto no tiene que ver con los victimarios sino con los que los estudian o imaginan. Frente a la pregunta sobre si los subalternos hablan, que es una pregunta sobre el objeto de estudio, la del perpetrador acaba siendo una pregunta dirigida al observador: ¿es posible hablar del perpetrador? En la medida en que en ese juego de tensiones y sinergias entre conocimiento y valoración la última palabra la tiene la dimensión moral, la identidad que está en juego en esta cuestión no es solo la del perpetrador objeto de estudio sino también la de su observador, el historiador, el científico social, el filósofo o el literato.

Chaputot nos recuerda que penetrar en la manera de ver el mundo del perpetrador es, en comparación con hacerlo con la de la víctima, "intellectuellement plus déstabilisant, humainement plus troublant et, à vrai dire, psychologiquement plus périlleux" (Chapoutot 19). Lo que se nos está diciendo es que, si uno quiere llegar a conocer 
acerca de los victimarios, la tarea que le espera no es solo ni en primer lugar acumular información y elaborar interpretaciones: se necesita de una postura moral que permita al observador sobreponerse a la desestabilización psicológica que el objetivo puede acarrear. Pero por ese mismo motivo su estudio no puede justificarse solo, como asume Chapoutot, "[p]our faire l'histoire, tout simplement". No. Para sobreponerse al conocimiento del mal ha de haber un motivo algo más acuciante para el observador, algo que ponga en juego su propia identidad, no como observador sino como sujeto que necesita también asegurarse un espacio moral para dar sentido a sus actos y a su vida en comunidad. Todo un aviso para los investigadores que en los próximos tiempos se adentrarán en esta temática en auge.

Hay además una recomendación especial que hacer a los que se acerquen al universo de los victimarios españoles. En una sociedad tan obsesionada con la cultura como lo ha sido la española a lo largo del siglo XX, es hasta cierto punto comprensible que los literatos, intelectuales y académicos en general se hayan convertido en un grupo irresponsable ante el público y los ciudadanos. Pero por ello mismo, señalar en los fascistas de primera hora su implicación con una maquinaria que produjo crímenes contra la humanidad deja de ser un ejercicio de simple conocimiento y pasa a serlo de reconocimiento, aunque en sentido negativo, es decir, como precondición del distanciamiento crítico respecto de los miembros de la particular 'República de las letras' posfranquista, una comunidad de miembros que en general se han obstinado en mantener a los ciudadanos atrapados en una película de amnesia instituida. En conclusión, necesitamos investigar acerca de los verdugos de los años treinta y cuarenta, y ello sin duda por motivos de conocimiento, pero muy especialmente también para liberarnos de los velos que, de cara al reconocimiento del mal, han venido estableciendo los intelectuales y académicos posfranquistas al exonerar a los autores clave de los crímenes contra la humanidad cometidos en el pasado predemocrático.

\section{Bibliografía}

Arendt, Hannah. Eichmann en Jerusalén. Un estudio sobre la banalidad del mal. Madrid: Lumen, 1999.

Bauman, Zygmunt. Modernidady Holocausto. Madrid/Buenos Aires/México: Sequitur, 2010.

Browing Christopher. Ordinary Men: Reserve Police Battalion 101 and the Final Solution in Poland. New York: Harper Collins, 1992.

Bruyne, Eddy de y Marc Rikmenspooel. For Rex and for Belgium: León Degrelle and Walloon Political and Military Collaboration, 1940-45. Solihull: Helion, 2004.

Cesarani, David. Becoming Eichmann. Cambridge: Da Capo Press, 2006.

Chapoutot, Johann. La révolution culturelle nazie. Paris: Gallimard, 2016.

Clément, Lucien Murielle. "Introduction." 'Les Bienveillantes' de Jonathan Littell. Études réunies. Ed. Lucien Murielle Clément. Amsterdam: Open Book Publishers, 2009. $1-10$. 
Devarrieux, Claire y Natalie Levisallies. "Les Bienveillantes, roman à controverse." Libération (7 noviembre 2006). Web. 2 julio 2018.

Ehrenreich, Barbara. "Foreword." Klaus Theweleit. Male Fantasies. Minneapolis: University of Minnesota Press, 1987. 9-17.

Galcerà i Padilla, David. Primo Levi y la Zona Gris. Barcelona: Universidad de Barcelona, 2014. PhD Thesis.

Gatti, Gabriel y María Martínez. "Presentación: el ciudadano-víctima. Notas para iniciar un debate." Revista de Estudios Sociales 59 (2017): 8-14. Web. 2 julio 2018.

Goldhagen, Daniel Jonah. Los verdugos voluntarios de Hitler. Los alemanes corrientes y el Holocausto. Madrid: Turner, 1997.

Hernández Cano, Eduardo. "El fascismo como respuesta a la crisis de autoridad del intelectual modernista: Ernesto Giménez Caballero, 1927-1935." Fascismo y Modernismo. Politica y cultura en la Europa de entreguerras (1918-1945). Ed. Francisco Cobo Romero, Claudio Hernández Burgos y Miguel Ángel del Arco Blanco. Granada: Comares, 2016. 261-75.

Labanyi, Jo. "Women, Asian Hordes and the Threat to the Self in Giménez Caballero's Genio de España." Bulletin of Hispanic Studies LXXIII/4 (1996): 377-87.

Lauge Hansen, Hans. "Víctimas y victimarios. Trauma social y representación de víctimas y victimarios en la novela española de memoria." Passés Futurs 3 (2018). Web. 28 septiembre 2018.

Levi, Primo. Si esto es un hombre. Barcelona: Muchnik, 1987.

Levi, Primo. Los hundidos y los salvados. Barcelona: Muchnik, 1989.

Lewy, Gunther. Perpetrators. The World of the Holocaust Killers. Oxford. Oxford University Press, 2017.

Linz, Juan J. y Alfred C. Stepan. Problems of Democratic Transition and Consolidation: Southern Europe, South America, and Post-communist Europe. Baltimore: Johns Hopkins University Press, 1996.

Littell, Jonathan. Las benévolas. Madrid: RBA, 2007.

Littell, Jonathan. Lo seco y lo búmedo. Madrid: RBA, 2009.

Loureiro, Ángel. Huellas del otro. Ética de la autobiografía en la modernidad española. Madrid: Postmetropolis Editorial, 2016.

Loureiro, Ángel. "Pathetic Arguments." Journal of Spanish Cultural Studies 9/2 (2008): $225-237$.

Mann, Michael. The Dark Side of Democracy. Explaining Ethnic Cleasing. Cambridge: Cambridge University Press, 2005.

Marín, Karmentxu. "Ernesto Giménez Caballero: 'El fascismo es un liberalismo desesperado..” El País (23 mayo 1979). Web. 2 julio 2018.

Martínez, Guillem. "El concepto CT." CT o la Cultura de la Transición. Crítica a 35 años de cultura española. Barcelona: Debolsillo, 2012. 13-24. 
Míguez Macho, Antonio. "A Genealogy of Genocide in Francoist Spain.” Genocide Studies and Prevention 8.1 (2006): 21-32.

Murat, Michel. "Faut-il brûler Les Bienveillantes ??" Revue critique de fixxion française contemporaine (2012). Web. 2 julio 2018.

Payne, Leigh A. y Aguilar, Paloma. Revealing New Truths about Spain's Violent Past. Londres: Palgrave Macmillan, 2016.

Pizzorno, Alessandro. "Algún otro tipo de alteridad. Una crítica de las teorías de la elección racional." Sistema 88 (1989): 27-42.

Rolland, Jacques. "Impotentia iudicandi. Notes sur Primo Levi." Etudes 3864 (1997): 493_ 501.

Sémelin. Jacques. Purifier et détruire. Usages politiques des massacres et génocides. Paris: Seuil, 2005.

Semprún, Jorge. Autobiografía de Federico Sánchez: Barcelona: Planeta, 1977.

Taylor, Charles. Fuentes del yo. La construcción de la identidad moderna. Barcelona: Paidós, 1996.

Theweleit, Klaus. Male Fantasies, vol. 1. Minneapolis: University of Minnesota Press, 1987.

Troubetzkoy, Wladimir. "Frères humains...': Les Bienveillantes, une histoire de familles." 'Les Bienveillantes' de Jonathan Littell. Études réunies. Ed. Lucien Murielle Clément. Amsterdam: Open Book Publishers, 2009. Web.

Umbral, Francisco. Leyenda del César visionario. Barcelona: Seix-Barral, 1991.

Welzer, Harald. Des executeurs. Des hommes normaux aux meurtriers de masse. Paris: Gallimard, 2007. 